demonstrate typical features. Rare conditions in which only a handful of cases have been described are also covered.

The book is aimed at dermatologists, but many conditions are the cutaneous manifestations of systemic infections and should be of interest to a wider "audience". Atypical presentations of common skin complaints frequently occur in HIV infection, and these are splendidly illustrated together with HIV specific conditions. Many rare conditions look very similar and the message seems to be: if in doubt, biopsy-the differential diagnosis may be wider than you think.

SARAH EDWARDS
International Congress of Sexually Transmitted Diseases

12th Meeting of the International Society for Sexually Transmitted Diseases Research (ISSTDR) held jointly with the International Union Against Venereal Diseases and Treponematoses (IUVDT) 19-22 October 1997, Sevilla, Spain.

For further information contact: ICSTD
Congress Secretariat, Apdo 6077, 41080Sevilla, SPAIN. Fax. 95.4377413.

\section{CORRECTION:}

In the paper STD control in developing countries by $M$ W Adler (Genitourin Med $1996 ; 72: 83-8)$ it should have been stated that the source of figure 1 was P Piot and L Fransen.

\section{NOTICES}

The International Society for Cutaneous Lymphomas

1 st Consensus Conference 14 June, HiltonHotel, Sydney. Contact: R Dummer, M D, Department of Dermatology, Gloriastr. 31, $\mathrm{CH}-8091 \mathrm{Zurich} /$ Switzerland.

\title{
DIARY OF EVENTS
}

3-6 July 1996

7-12 July 1996

11-14 Sept 1996

15-18 Sept 1996

18-20 Sept 1996

3-7 Nov 1996

1-5 Dec 1996
Fifth International Drug Resistance Workshop. Whistler, Canada. International AIDS Conference, Vancouver, Canada.

Third European Chlamydia Meeting, Vienna, Austria.

Interscience Conference on Antimicrobial Agents and Chemotherapy (ICAAC). New Orleans, USA.

Society for Social Medicine. Dundee, UK.

3rd International Congress on Drug Therapy in HIV Infection. Birmingham, UK

International Papillomavirus Workshop, Queensland, Australia. 